\title{
Institutional Review Board Independent Ethics Committee Informed Consent Document
}

National Cancer Institute

\section{Source}

National Cancer Institute. Institutional Review Board Independent Ethics Committee

Informed Consent Document. NCI Thesaurus. Code C115697.

Records approved by the Institutional Review Board (IRB)/Independent Ethics Committee (IEC), explaining study information to assist study volunteers in understanding the expectations and requirements of trial participation. 